Abstract

\title{
Evaluating Spatial and Temporal Fragmentation of a Categorical Variable Using New Metrics Based on Entropy: Example of Vegetation Land Cover ${ }^{+}$
}

\author{
Didier Guy Leibovici ${ }^{1}$, Christophe Claramunt ${ }^{2}$ and Shaun Quegan ${ }^{1}$ \\ 1 University of Sheffield, Sheffield, UK \\ 2 IRENav (Naval Academy Research Institute), Brest, France \\ † Presented at the Entropy 2021: The Scientific Tool of the 21st Century, 5-7 May 2021; Available online: \\ https://sciforum.net/conference/Entropy2021/.
}

Published: 5 May 2021

Associated with climate change and/or land use pressure, forest fragmentation is a spatiotemporal shrinking process that reduces the sizes of forest patches. This breaks up forest patches so increasing their number before the small ones progressively disappear. Fragmentation can be assessed spatially as a level of the current status of the fragmented spatial configuration and temporally as the level of the speed of the fragmentation process itself. Among the different landscape metrics based on patches as indicative measures for fragmentation, the Shannon entropy of the observed spatial distribution of categories has been of particular interest. Based on a recently suggested spatio-temporal entropy framework focusing on patch size and shape distributions, this paper shows how to derive useful fragmentation metrics at local and global levels, spatially, temporally or both. Moreover, it shows that using fully symmetric approaches between space, time and category within this framework, can lead to more sensitive fragmentation metrics as well as providing complementary local approach for cartographic representation. Land cover data simulations from land surface modelling to a 2100 horizon are used to illustrate the proposed fragmentation metrics.

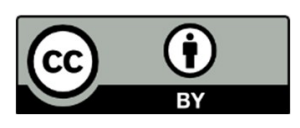

(C) 2021 by the authors. Licensee MDPI, Basel, Switzerland. This article is an open access article distributed under the terms and conditions of the Creative Commons Attribution (CC BY) license (http://creativecommons.org/licenses/by/4.0/). 